\title{
Optimization and Study of the Response Surface of Properties for the Synthesis of ZSM-5 Zeolites with Hierarchical Pore Structure Obtained by Desilication
}

\author{
Holman J. Mesa, ${ }^{a}$ Arnaldo C. Faro Jr. ${ }^{a}$ and Victor O. Rodrigues ${ }^{\circledR} * a$ \\ ${ }^{a}$ Laboratório de Catálise Heterogênea, Instituto de Química, \\ Universidade Federal do Rio de Janeiro, Av. Athos da Silveira Ramos, 149, 302/A, \\ 21941-909 Rio de Janeiro-RJ, Brazil
}

\begin{abstract}
Hierarchical ZSM-5 zeolites were prepared by alkali treatment (desilication) at two temperatures, two reaction times, and two $\mathrm{NaOH}$ concentrations. A $2^{3}$ factorial design was used to study the effect of these variables on the crystallinity, microporosity, and mesoporosity of the zeolite due to the desilication treatment. The factorial design analysis showed that the temperature, reaction time and $\mathrm{NaOH}$ concentration and the second order interaction between temperature and time have statistically significant effect on the micropore volume. On mesopore volumes $\left(\mathrm{V}_{\text {meso }}\right)$ and areas $\left(\mathrm{S}_{\text {meso }}\right)$, the reaction time and $\mathrm{NaOH}$ concentration factors have statistically significant effects. In the case of mesopore volumes, the second order reaction time and $\mathrm{NaOH}$ concentration interaction factor are also significant. On the other hand, only the alkali concentration affected, negatively, the relative crystallinity. Two hierarchical ZSM-5 zeolites with the highest relative crystallinity and mesoporosity were selected and further characterized by inductively coupled plasma (ICP) analysis, ${ }^{29} \mathrm{Si}$ nuclear magnetic resonance (NMR), ${ }^{27} \mathrm{Al}$ NMR, Fourier transform infrared (FTIR) spectroscopy in the $\mathrm{OH}$ stretch region and pyridine adsorbed FTIR spectroscopy. NMR and FTIR results showed that the alkali treatment selectively removed silica from the zeolite framework, decreasing the SAR (silica-to-alumina ratio) values, while decreasing Brønsted acid site concentrations and increasing Lewis acid sites concentrations.
\end{abstract}

Keywords: desilication, factorial design, hierarchical zeolites, ZSM-5

\section{Introduction}

Zeolites are widely known for their molecular sieve (both in adsorption processes and catalysis) and ion exchange properties. ${ }^{1-7}$ However, the zeolites main usage is in heterogeneous catalysis, where they are employed in an infinity of industrial processes: hydroisomerization, cracking, hydrotreatments, MTG ("methanol to gasoline") process, etc. ${ }^{8-13}$ Many of the zeolite properties, such as high surface areas, hydrophilicity, molecular sieving, and shape selectivity, are responsible for their versatility and great importance in the chemical industry. ${ }^{14,15}$

Nevertheless, the most important zeolite property explored in catalytic processes in the chemical industry is their shape selectivity, or, in other words, their ability to favor certain reaction pathways based on the size relationship between their cavities and molecules (reagents, products or transition states) when reactions take place in a restricted environment. ${ }^{16,17}$ Specifically, in the case of the

*e-mail: vicerodrigues@iq.ufrj.br
ZSM-5 zeolite, shape selectivity is due to an intricate set of interconnecting linear and sinusoidal channels that are part of the zeolite framework. . $^{18,19}$

One of the drawbacks of this sterically hindered set of channels is the restriction of molecular diffusion inside the zeolite crystal, decreasing the apparent reaction rates in these kinetic systems, an effect known as internal diffusional limitations. ${ }^{20}$ Many strategies have been used in the literature to reduce these internal diffusional limitations, one of the most popular approaches being the introduction of a second set of pores inside the ZSM-5 structure, but with diameters in the order of magnitude of mesopores. In this new set of mesopores, molecules can rapidly diffuse through the structure, improving the contact between catalytic active sites and fluid phase..$^{20,21}$ These zeolites are said to have a hierarchical pore structure.

ZSM-5 zeolites with hierarchical pore structures have a wide range of applications in catalytic reactions, such as olefin aromatization, methanol-to-hydrocarbons (MTH), isomerization, cracking, etc., mainly due to their enhanced catalytic activities, selectivities, and hydrothermal 
stabilities. ${ }^{22-25} \mathrm{~A}$ vast number of methodologies has been employed in the synthesis of ZSM-5 zeolites with hierarchical pore structure, but these are often classified in two major groups: (i) bottom-up: the zeolite is synthesized with the addition of a secondary template for the mesopores (carbon black or long-chain alkane molecules are common examples); ${ }^{20,26-31}$ or (ii) top-down: an already synthesized zeolite is exposed to a destructive agent, such as hightemperature steam or alkali solution, creating the desired size efects. ${ }^{13,30-36}$

Among the top-down methods, silicon etching of a zeolite structure through reaction with an alkali (usually sodium hydroxide), a desilication method, is a simple and cheap method to produce hierarchical ZSM-5 zeolites. However, as this is a destructive method, side effects such as pore structure collapse and crystallinity loss during the reaction are usually a problem..$^{37,38}$

The desilication procedure in alkaline media has been extensively applied to many types of zeolites, ${ }^{39-42}$ where optimal conditions were established (especially the time and temperature) on the mesopore properties. In most procedures, the zeolite samples were treated with $0.2 \mathrm{~mol} \mathrm{~L}^{-1} \mathrm{NaOH}$ solutions for $30 \mathrm{~min}$ at $358 \mathrm{~K}^{.23,31,32,38,43,44}$ However, there is a lack of studies regarding the effects of temperature, reaction time and alkali concentration on the crystallinity, mesoporosity, and microporosity of the ZSM-5 zeolites obtained by desilication treatment.

Therefore, in the present paper, we focus on the optimization and study of the response surface of the synthesis of ZSM-5 zeolites with hierarchical pore structure by means of a $2^{3}$ complete factorial design using time, temperature and alkali concentration as variables, as well as the study of Lewis and Brønsted acidity and character of the hydroxyl groups present in selected samples with optimized textural properties and crystallinity after the desilication treatment. As far as our knowledge goes, this systematic study of zeolite desilication has not been explored in the literature so far.

\section{Experimental}

\section{Synthesis of the materials}

The commercial zeolite used in this work was supplied by Zeolyst (CBV 5524G, Kansas, USA) in ammonium form with a $\mathrm{Si} / \mathrm{Al}$ ratio of 50 , confirmed by inductively coupled plasma (ICP) analysis. In order to obtain the zeolite in its acidic form, it was calcined under air flow $\left(100 \mathrm{~cm}^{3} \mathrm{~min}^{-1} \mathrm{~g}^{-1}\right)$ at $773 \mathrm{~K}$ for $4 \mathrm{~h}$. This microporous support (HZSM-5) is denominated untreated zeolite.

The introduction of mesoporosity in HZSM-5 was accomplished by means of a desilication procedure, based on the method described by Groen et al. ${ }^{45}$ and Tempelman et $a l .{ }^{46} \mathrm{~A} 2^{3}$ factorial design was used to study how the microporosity, mesoporosity, and crystallinity of the HZSM-5 zeolite depended on temperature, reaction time, and alkali concentration used in the treatment. The complete factorial design using three variables at two levels each, required $2^{3}=8$ experiments. Two temperature levels (338 and $358 \mathrm{~K}$ ), two reaction times (30 and $120 \mathrm{~min}$ ) and two sodium hydroxide (99\%, Vetec-Sigma, Saint Louis, USA) solution concentrations ( 0.30 and $0.65 \mathrm{~mol} \mathrm{~L}^{-1}$ ) were used. The list of these combinations, called "design table", is presented in Table 1 below. Table 1 lists the variable levels with the symbols - for the lower level and + for the higher level. Accordingly, the sample nomenclature adopted consisted of HZM-5 followed by three + or - symbols denoting the levels of each variable, temperature, time and concentration, in this order. Samples HZSM-5- + - and HZSM-5+ + - were synthesized and analyzed as duplicates, and their duplicate results were included in the factorial design to add more degrees of freedom and reduce statistical error in our calculations.

Table 1. $2^{3}$ complete factorial analysis design table

\begin{tabular}{|c|c|c|c|c|c|c|c|}
\hline \multirow{2}{*}{ Factor } & & & & & \multicolumn{3}{|c|}{ Level } \\
\hline & & & & & - & & + \\
\hline 1 & \multicolumn{4}{|c|}{ temperature / K } & 338 & & 358 \\
\hline 2 & \multicolumn{4}{|c|}{ time / min } & 30 & & 120 \\
\hline 3 & \multicolumn{4}{|c|}{ concentration / $\left(\mathrm{mol} \mathrm{L}^{-1}\right)$} & 0.30 & & 0.65 \\
\hline Sample & Average & 1 & 2 & 3 & 12 & 13 & 23 \\
\hline HZSM-5- - - & + & - & - & - & + & + & + \\
\hline HZSM-5+-- & + & + & - & - & - & - & + \\
\hline HZSM-5- +- & + & - & + & - & - & + & - \\
\hline HZSM-5+ +- & + & + & + & - & + & - & - \\
\hline HZSM-5--+ & + & - & - & + & + & - & - \\
\hline HZSM-5+-+ & + & + & - & + & - & + & - \\
\hline HZSM-5- + + & + & - & + & + & - & - & + \\
\hline HZSM-5+ + + & + & + & + & + & + & + & + \\
\hline
\end{tabular}

Zeolites with synthesis conditions selected as optimal, i.e., those that showed increased mesopore generation (mesopore volumes $\left(\mathrm{V}_{\text {meso }}\right)$ and areas $\left.\left(\mathrm{S}_{\text {meso }}\right)\right)$ with the least micropore volume $\left(\mathrm{V}_{\text {micro }}\right)$ and crystallinity losses $\left(\mathrm{C}_{\mathrm{XRD}}\right)$, were prepared in larger amounts as follows, for extended characterization.

A $2.00 \mathrm{~g}$ mass of the commercial zeolite, previously dried in static air at $393 \mathrm{~K}$ for $12 \mathrm{~h}$, was vigorously stirred at $200 \mathrm{rpm}$ in $100 \mathrm{~mL}$ of a $0.30 \mathrm{~mol} \mathrm{~L}^{-1} \mathrm{NaOH}$ solution at 358 or $338 \mathrm{~K}$ for $120 \mathrm{~min}$. The zeolites obtained were denoted as HZSM-5(358K) and HZSM-5(338K), respectively. 
After the desilication procedure, the suspension was filtered and washed with abundant amounts of hot deionized water until the $\mathrm{pH}$ in the waste waters reached the same value as in the source and finally dried overnight at $393 \mathrm{~K}$ in static air. The samples treated with the alkali solution were ion-exchanged to the ammoniacal form by three successive $4 \mathrm{~h}$ exchanges with $1.2 \mathrm{~mol} \mathrm{~L}^{-1} \mathrm{NH}_{4} \mathrm{Cl}(99.5 \%$ from Vetec-Sigma, Saint Louis, USA) solution at $323 \mathrm{~K}$. The conversion from the ammoniacal to the protonic form used the same calcination procedure described earlier.

\section{Zeolite characterization}

The textural properties of the zeolites were determined by $\mathrm{N}_{2}$ physisorption at $77 \mathrm{~K}$ on a Micrometrics ASAP-2010 system (Norcross, USA) in static measurement mode. Micropore volumes $\left(\mathrm{V}_{\text {micro }}\right)$ were calculated by the t-plot method and mesopore volumes $\left(\mathrm{V}_{\text {meso }}\right)$ and areas $\left(\mathrm{S}_{\text {meso }}\right)$ were calculated from cumulative adsorbed volumes using the Barrett-Joyner-Halenda (BJH) method on the adsorption branch of the isotherms in the range $2-50 \mathrm{~nm}$. The samples were pretreated under vacuum at $573 \mathrm{~K}$ until a degassing rate lower than $2 \mu \mathrm{mHg} \mathrm{min}{ }^{-1}$ was achieved.

Powder X-ray diffraction (XRD) analysis was carried out using a Rigaku IV equipment (Tokyo, Japan) with $\mathrm{Cu} \mathrm{K} \alpha$ radiation $(40 \mathrm{kV}, 20 \mathrm{~mA}), \lambda=0.15406 \mathrm{~nm}$, in the $2 \theta 5-70^{\circ}$ range. These results were used to observe the effect of the alkali treatment on the crystal structure of the supports and also to calculate the relative crystallinity to the untreated sample (which was considered to be $100 \%$ ) from the integration of the intensity peaks in the $2 \theta=20-25^{\circ}$ range. ${ }^{47,48}$

Infrared (IR) spectral analysis in the $\mathrm{OH}$ stretching and adsorbed pyridine ranges were performed using a Nicolet 6700-FTIR spectrometer (Waltham, USA) between $4000-700 \mathrm{~cm}^{-1}$ using self-supported thin wafers of the catalysts with a mass/surface ratio of approximately $8 \mathrm{mg} \mathrm{cm}^{-2}$. The samples were pretreated under vacuum at $673 \mathrm{~K}$ for $4 \mathrm{~h}$ using the system described by Rodrigues et al. ${ }^{49}$

The determination of the infrared spectrum in the $\mathrm{OH}$ stretching region was performed after sample treatment under vacuum for $4 \mathrm{~h}$ at $673 \mathrm{~K}$. This spectrum was used as background for the pyridine adsorption experiments. Pyridine (99.9\%, Sigma-Aldrich, Saint Louis, USA) was adsorbed at $323 \mathrm{~K}$ at an equilibrium pressure of 5.0 torr for $1 \mathrm{~h}$. A spectrum was recorded once the cell was cooled and after pyridine evacuation at $523 \mathrm{~K}$ for $10 \mathrm{~min}$ based on the methodology used by Rodrigues et al.$^{49}$

The Al and Si contents of the samples were determined by inductively coupled plasma optical emission spectroscopy
(ICP-OES) in a Spectro Arcos spectrometer (Kleve, Germany) equipped with a free-running 27.12 MHz generator at $1400 \mathrm{~W}$. Prior to analysis, samples were digested in a $\mathrm{HF} / \mathrm{H}_{3} \mathrm{BO}_{3}(1: 12)$ mixture.

Magic angle spinning nuclear magnetic resonance (MAS NMR) analyses of ${ }^{29} \mathrm{Si}$ and ${ }^{27} \mathrm{Al}$ were made in a Bruker spectrometer, model Advance III 400 (9.4 T, Billerica, USA). The spectra were obtained using CP-MAS Bruker nuclear probe with $4 \mathrm{~mm}$ zircon rotors and rotation frequencies of 5 and $12 \mathrm{kHz}$ for ${ }^{29} \mathrm{Si}$ and ${ }^{27} \mathrm{Al}$, respectively, with samples previously equilibrated with water vapor at room temperature. The ${ }^{27} \mathrm{Al}$ measurements were obtained with 1024 scans in $0.50 \mathrm{~s}$ interval pulses, while the ${ }^{29} \mathrm{Si}$ measurements were obtained using 1000 scans and $60 \mathrm{~s}$ pulse interval. The framework $\mathrm{Si} / \mathrm{Al}$ ratio was determined by deconvolution of the ${ }^{29} \mathrm{Si} \mathrm{NMR}$ signal using the formula in equation $1 .^{50,51}$

$$
\left(\frac{\mathrm{Si}}{\mathrm{Al}}\right)_{\mathrm{Fw}}=\frac{4 \sum_{\mathrm{n}=0}^{4} I_{\mathrm{n}}}{\sum_{\mathrm{n}=0}^{4} \mathrm{n} \cdot \mathrm{I}_{\mathrm{n}}}
$$

where $I_{n}$ represents the area under a given peak corresponding to a $\mathrm{Si}$ atom connected (by bridging oxygen atoms) to $\mathrm{n} \mathrm{Al}$ atoms, where $\mathrm{n}$ can be $0,1,2,3$ or 4 .

\section{Results and Discussion}

Factorial design analysis for the alkali treatment of the zeolites

A $2^{3}$ complete factorial design was used to study how the microporosity $\left(\mathrm{V}_{\text {micro }}\right)$, mesoporosity $\left(\mathrm{V}_{\text {meso }}\right.$ and $\left.\mathrm{S}_{\text {meso }}\right)$, and crystallinity $\left(\mathrm{C}_{\mathrm{XRD}}\right)$ of the HZSM-5 zeolite depend on the temperature (1), reaction time (2) and alkali concentration (3) used in the treatment, for which the design table was already shown in the Experimental section (Table 1).

Table 2 shows the obtained values for these properties, along with those of the parent HZSM-5 zeolite. It can be noticed that, in general, the alkali treatment affects the textural and structural properties of the zeolite.

If we analyze the columns in Table 2 for micropore volume and crystallinity determined by XRD, we can determine that both are decreased by the alkali treatment, probably due to the loss of structural integrity by the zeolite, due to silicon etching. On the other hand, analyzing the columns for mesopore volume and area, both are, in the majority of our samples, increased by the alkali treatment, a behavior also already expected, since silicon etching will create holes in the zeolite structure which can be connected leading to the formation of mesopore channels. 
Table 2. Micropore volume $\left(\mathrm{V}_{\text {micro }}\right)$, mesopore volume $\left(\mathrm{V}_{\text {meso }}\right)$, mesopore area $\left(\mathrm{S}_{\text {meso }}\right)$ and relative crystallinity $\left(\mathrm{C}_{\mathrm{XRD}}\right)$ for the $2^{3}$ complete factorial analysis samples

\begin{tabular}{lcccc}
\hline Sample & $\begin{array}{c}\mathrm{V}_{\text {micro }} / \\
\left(\mathrm{cm}^{3} \mathrm{~g}^{-1}\right)\end{array}$ & $\begin{array}{c}\mathrm{V}_{\text {meso }} / \\
\left(\mathrm{cm}^{3} \mathrm{~g}^{-1}\right)\end{array}$ & $\begin{array}{c}\mathrm{S}_{\text {meso }} / \\
\left(\mathrm{m}^{2} \mathrm{~g}^{-1}\right)\end{array}$ & $\mathrm{C}_{\text {XRD }}{ }^{\mathrm{a}} / \%$ \\
\hline HZSM-5 & 0.13 & 0.10 & 49.9 & 100 \\
HZSM-5- - - & 0.11 & 0.08 & 27 & 100 \\
HZSM-5+-- & 0.07 & 0.07 & 40 & 88 \\
HZSM-5- +- & 0.10 & 0.17 & 83 & 105 \\
HZSM-5- +- ${ }^{\mathrm{b}}$ & 0.11 & 0.18 & 83 & 102 \\
HZSM-5++- & 0.11 & 0.18 & 77 & 91 \\
HZSM-5+ +- & 0.11 & 0.19 & 83 & 89 \\
HZSM-5- - + & 0.08 & 0.19 & 106 & 85 \\
HZSM-5+- + & 0.03 & 0.17 & 83 & 43 \\
HZSM-5- + + & 0.05 & 0.20 & 108 & 58 \\
HZSM-5+ + + & 0.07 & 0.19 & 108 & 66 \\
\hline
\end{tabular}

${ }^{a}$ Relative crystallinity determined by XRD analysis; ${ }^{\text {bsamples }}$ HZSM-5- + - and HZSM-5+ + - were synthesized and characterized as duplicates.

The design and response tables (Tables 1 and 2, respectively) can be used in the construction of a statistical model characterized by the contrast coefficients that describe the linear dependence of each property on the variation of each of the factors and their interactions, as shown in equation 2.

$\hat{\mathbf{y}}=\mathrm{b}_{0}+\mathrm{b}_{1} \mathrm{~T}+\mathrm{b}_{2} \mathrm{t}+\mathrm{b}_{3} \mathrm{C}+\mathrm{b}_{12} \mathrm{~T} \cdot \mathrm{t}+\mathrm{b}_{13} \mathrm{~T} \cdot \mathrm{C}+\mathrm{b}_{23} \mathrm{t} \cdot \mathrm{C}$

where $\mathrm{T}$ is the temperature, $\mathrm{t}$ is the contact time, $\mathrm{C}$ the $\mathrm{NaOH}$ concentration, $\hat{\mathbf{y}}$ is the property (response), $\mathrm{b}_{0}$ is the linear coefficient, $b_{1}, b_{2}, b_{3}$ are the coefficients of the principal factors temperature, reaction time and $\mathrm{NaOH}$ concentration, respectively, and $b_{12}, b_{13}, b_{23}$ are the coefficients of the interaction between any two factors. Interactions between three factors are extremely rare, being attributed to random fluctuations in the process, and, therefore, were not included in our model to increase the number of degrees of freedom during error analysis. The significance of the effects of each variable was evaluated with analysis of variances
(ANOVA) with $95 \%$ confidence interval to assess the statistical significance of the coefficients. A $p$-value of less than 0.05 was considered significant. The values of the linear coefficients and interactions proposed in equation 2 are shown in Table 3 below. Pareto charts of standardized effects for all responses, $\mathrm{V}_{\text {micro }}, \mathrm{V}_{\text {meso }}, \mathrm{S}_{\text {meso }}$ and $\mathrm{C}_{\mathrm{XRD}}$ are shown in Figure 1 along with the $p=0.05$ significance limit. The ANOVA results for all responses considered in this work are shown in Tables S1, S2, S3 and S4 available in the Supplementary Information section.

Analyzing the Pareto plot in Figure 1a, it is observed that the first-order effects for temperature $\left(b_{1}\right)$, reaction time $\left(b_{2}\right)$ and alkali concentration $\left(b_{3}\right)$, and the secondorder interaction between temperature and reaction time $\left(b_{12}\right)$ affected significantly the micropore volume $\left(\mathrm{V}_{\text {micro }}\right)$ of the zeolites.

A decrease in $\mathrm{V}_{\text {micro }}$ is observed when the $\mathrm{NaOH}$ concentration (3) is increased. This behavior has already been reported in the literature ${ }^{46-48}$ and is probably due to the presence of amorphous Si-rich debris and destruction of micropores due to silicon etching. Also, the increase in temperature (1) leads to a decrease in the micropore volume, due to an increase in the rate of desilication. An increase in reaction time (2) or the combined increase in temperature and reaction time $\left(b_{12}\right)$, however, lead to a substantial increase in micropore volume. These observations indicate that an aging or annealing effect must predominate under these conditions.

When we consider the Pareto chart in Figure $1 \mathrm{~b}$ for the $\mathrm{V}_{\text {meso }}$ response, it is observed that the effects of time $\left(\mathrm{b}_{2}\right)$, alkali concentration $\left(b_{3}\right)$ and their second-order interaction $\left(b_{23}\right)$ are relevant. On the other hand, it can be observed that all effects involving the temperature (1), irrespective of their order $\left(b_{1}, b_{12}\right.$ and $\left.b_{13}\right)$, did not affect the $\mathrm{V}_{\text {meso }}$ response.

When there is an increase in $\mathrm{NaOH}$ concentration (3) or in the reaction time (2), there is a positive contribution to the mesopore volume as shown by the values of $b_{3}$ and $\mathrm{b}_{2}$, respectively. This is already expected, as an increase in alkali concentration (3) will improve the extent of silicon etching from the zeolite structure. The positive

Table 3. Results of the $2^{3}$ complete factorial design for the HZSM-5 zeolite alkali treatments. The considered effects are temperature (1), time (2), concentration (3) and their second-order interactions

\begin{tabular}{|c|c|c|c|c|c|c|c|}
\hline \multirow{2}{*}{$\begin{array}{l}\text { Property } \\
\hat{\mathbf{y}}\end{array}$} & \multicolumn{7}{|c|}{ Factorial design effect } \\
\hline & $\mathrm{b}_{0}$ & $\mathrm{~b}_{1}$ & $\mathrm{~b}_{2}$ & $\mathrm{~b}_{3}$ & $b_{12}$ & $\mathrm{~b}_{13}$ & $\mathrm{~b}_{23}$ \\
\hline$\overline{\mathrm{V}_{\text {micro }} /\left(\mathrm{cm}^{3} \mathrm{~g}^{-1}\right)}$ & 0.07970 & -0.00809 & 0.00692 & -0.01895 & 0.01418 & 0.00076 & -0.00432 \\
\hline $\mathrm{V}_{\text {meso }} /\left(\mathrm{cm}^{3} \mathrm{~g}^{-1}\right)$ & 0.15992 & -0.00352 & 0.02842 & 0.02963 & 0.00432 & -0.00471 & -0.02414 \\
\hline $\mathrm{S}_{\mathrm{meso}} /\left(\mathrm{m}^{2} \mathrm{~g}^{-1}\right)$ & 79.38 & -2.35 & 15.20 & 21.85 & 0.19 & -3.47 & -8.63 \\
\hline $\mathrm{C}_{\mathrm{XRD}} / \%$ & 79.19 & -8.36 & 0.19 & -16.19 & 5.14 & -0.14 & -1.19 \\
\hline
\end{tabular}

$\mathrm{V}_{\text {micro }}$ : micropore volume; $\mathrm{V}_{\text {meso }}:$ mesopore volumes; $\mathrm{S}_{\text {meso }}$ : mesopore area; $\mathrm{C}_{\mathrm{XRD}}$ : crystallinity losses; $\hat{\mathbf{y}}$ : property (response); $\mathrm{b}_{0}$ : linear coefficient; $b_{1}, b_{2}, b_{3}$ : coefficients of the principal factors. 
(a)

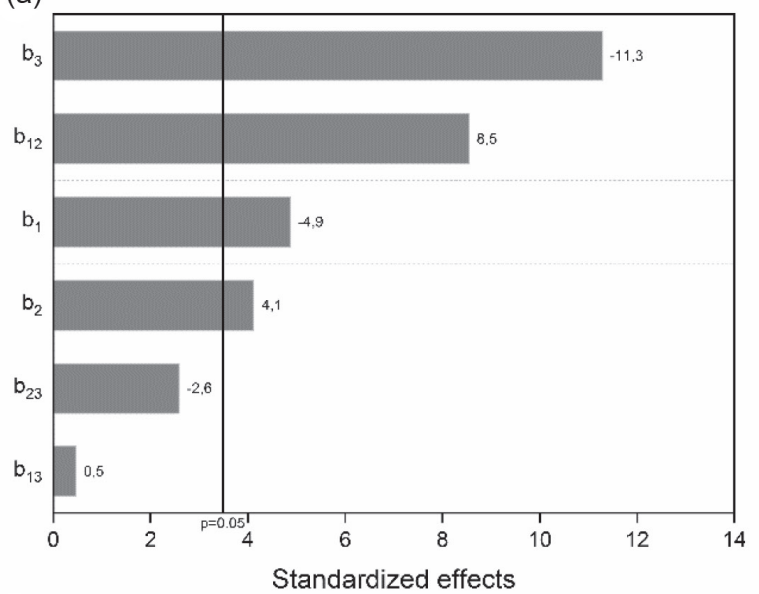

(c)

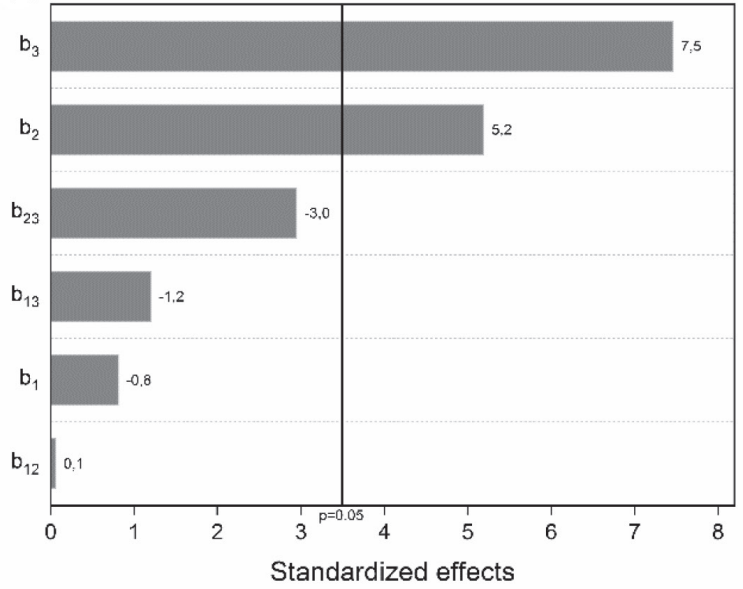

(b)

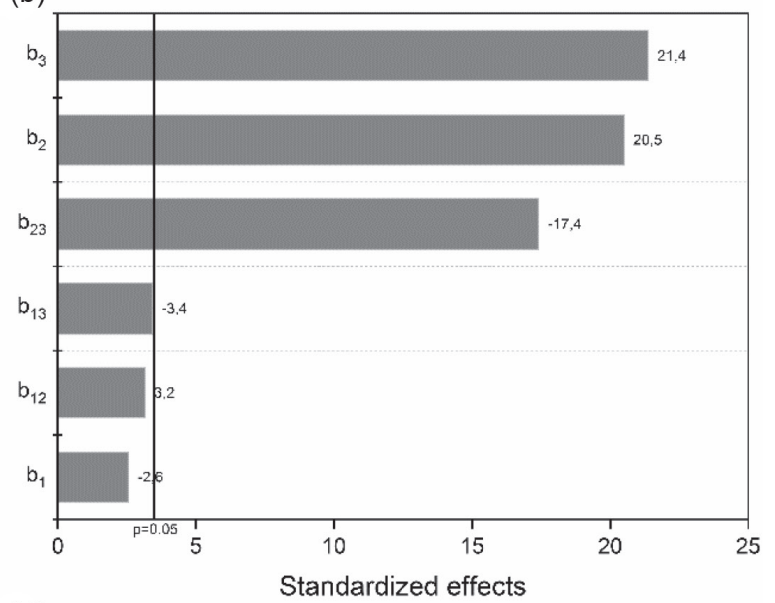

(d)

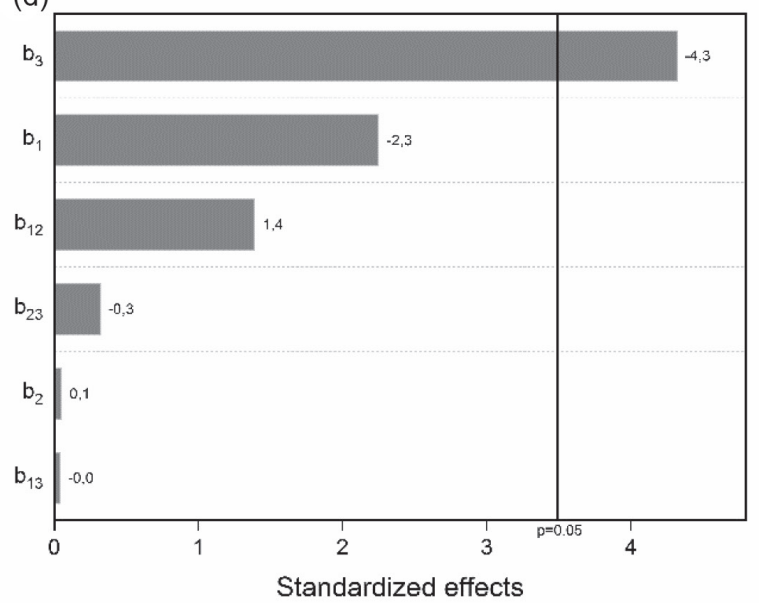

Figure 1. Pareto charts from $2^{3}$ factorial design for the following responses: (a) micropore volume $\left(\mathrm{V}_{\text {micro }}\right)$; (b) mesopore volume $\left(\mathrm{V}_{\text {meso }}\right)$; (c) mesopore area $\left(\mathrm{S}_{\text {meso }}\right)$ and $(\mathrm{d})$ crystallinity $\left(\mathrm{C}_{\mathrm{XRD}}\right)$. The considered effects are 1: temperature, 2: time, 3: concentration and their second-order interactions. The vertical line indicates the $p=0.05$ significance limit.

contribution of reaction time (2) to $\mathrm{V}_{\text {meso }}$ can be attributed to the necessity of more time to connect the defects created into a mesopore network. On the other hand, if we evaluate the second order interaction between reaction time and $\mathrm{NaOH}$ concentration factor $\left(\mathrm{b}_{23}\right)$, it will have a negative impact with the same order of magnitude as the first order factors. This observation must seem odd at first glance, but its interpretation is, nevertheless, simple: under the studied conditions, there is a limit to the mesopore volume obtained by desilication (ca. $19 \mathrm{~cm}^{3} \mathrm{~g}^{-1}$ ) which can be achieved, either by an increase in reaction time (2), or alkali concentration (3), and the simultaneous increase in both variables does not lead to an enhanced effect in the $\mathrm{V}_{\text {meso }}$ response. This same interpretation can be applied to the influence of the studied factors on the mesopore area response, with the exception that, in this case, the second-order interaction between reaction time and alkali concentration $\left(b_{23}\right)$ is not significant according to the Pareto chart in Figure 1c. This indicates that an upper limit in $\mathrm{S}_{\text {meso }}$ does not exist under our studied conditions.
Finally, in the experimental conditions used in this paper for the desilication process, only the $\mathrm{NaOH}$ concentration $\left(b_{3}\right)$ was a statistically relevant factor in the relative crystallinity $\left(\mathrm{C}_{\mathrm{XRD}}\right)$ analysis according to the Pareto chart in Figure 1d. When the concentration is increased from 0.30 to $0.65 \mathrm{~mol} \mathrm{~L}^{-1}$, it is possible to observe a loss in the crystallinity of up to $57 \%$. Therefore, increasing the $\mathrm{NaOH}$ concentration (3) increases Si etching and, in the harsher conditions, even $\mathrm{Al}$ extraction from the framework occurs, leading to the collapse of the zeolite structure, while the removed species can remain as amorphous material in the solid. This interpretation is strengthened when a fairly linear correlation between the crystallinity and the micropore volume is evidenced in Figure 2.

It is important to notice that, among the crystallinity values obtained in this work, two values above $100 \%$ were detected in both replicates of sample HZSM-5-+Although a crystallinity value above $100 \%$ may appear unusual, it is possible in the present case, taking into account that the sample used as reference for our XRD crystallinity 


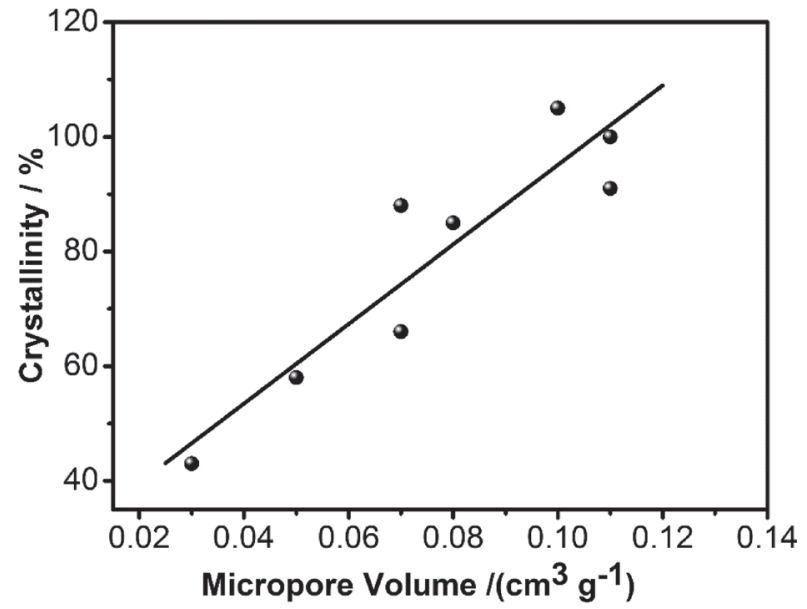

Figure 2. Correlation between crystallinity and micropore volume of the zeolites.

determinations was a commercial untreated zeolite that may contain amorphous silica impurities. During the alkali treatment, these impurities are preferentially dissolved increasing the overall sample crystallinity.

Based on the results in Table 2, two treatment conditions were selected for the preparation of the mesoporous zeolites to be further characterized. Our aim was to select mesoporous supports with increased mesopore volume and area that retained most of its micropore volume and crystallinity when compared to the untreated HZSM-5. With basis on these guidelines, the conditions selected were (i) HZSM-5 treatment with $0.30 \mathrm{~mol} \mathrm{~L}^{-1} \mathrm{NaOH}$ solution at $358 \mathrm{~K}$ for $120 \mathrm{~min}$; and (ii) these same conditions but at the temperature of $338 \mathrm{~K}$. The mesoporous supports are, respectively, samples HZSM-5+ + - and HZSM-5- + - in Table 1.

\section{Characterization of the optimized supports}

Chemical analysis and ${ }^{27} \mathrm{Al}$ and ${ }^{29} \mathrm{Si}$ solid-state NMR results are displayed in Table 4. Figure 3 shows the MAS ${ }^{27} \mathrm{Al}$ NMR spectra for the optimized supports.

The results show a lower $\mathrm{Si} / \mathrm{Al}$ ratio on the alkali-treated materials as compared to the untreated one, measured by

Table 4. Chemical analysis and NMR results supports and catalysts

\begin{tabular}{lcccc}
\hline Sample & $\mathrm{ICP} \mathrm{Si} / \mathrm{Al}^{\mathrm{a}}$ & ${\mathrm{NMR} \mathrm{Si} / \mathrm{Al}^{\mathrm{b}}}^{\mathrm{O}}$ & $\mathrm{O}_{\mathrm{h}} \mathrm{Al}^{\mathrm{c}} / \%$ & $\mathrm{Td} \mathrm{Al}^{\mathrm{d}} / \%$ \\
\hline HZSM-5 & 47.8 & 49.2 & 2.5 & 97.5 \\
HZSM-5(358K) & 44.4 & 43.4 & 4.2 & 95.8 \\
HZSM-5(338K) & 38.4 & 43.0 & 1.2 & 98.8 \\
\hline
\end{tabular}

a $\mathrm{Si} / \mathrm{Al}$ relation determined by inductively coupled plasma (ICP) analysis; ${ }^{\mathrm{b}}$ framework Si/Al relation determined by ${ }^{29} \mathrm{Si}$ nuclear magnetic resonance (NMR); cextra-framework aluminum species in octahedral coordination

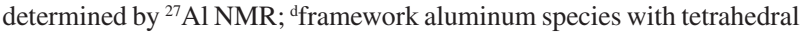
coordination determined by ${ }^{27} \mathrm{Al} \mathrm{NMR}$.

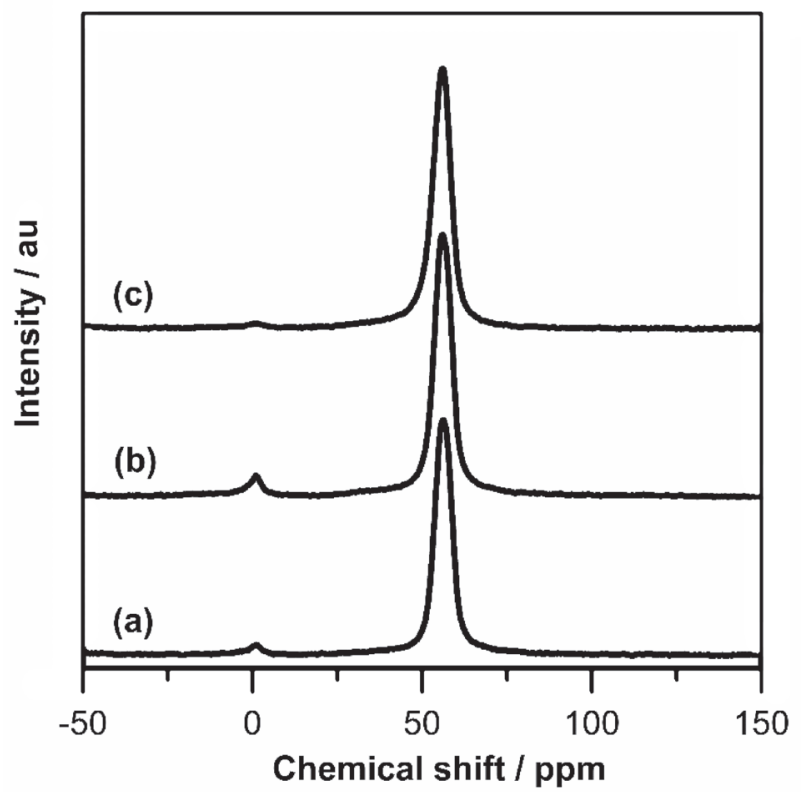

Figure 3. ${ }^{27} \mathrm{Al}$ MAS NMR spectra of (a) HZSM-5; (b) HZSM-5(358K) and (c) HZSM-5(338K).

both ICP (bulk) and NMR (framework). This demonstrates the preferential dissolution of $\mathrm{Si}$ with respect to $\mathrm{Al}$ in the zeolite structure under the conditions used. This result was also observed by Groen et $_{\text {al. }}{ }^{38}$

The amount of octahedrally coordinated aluminum $\left(\% \mathrm{O}_{\mathrm{h}}\right)$ is smaller in HZSM- $5(338 \mathrm{~K})$ than in the untreated zeolite. One possible explanation is that extra-framework aluminum might have been leached during alkali treatment. However, this is unlikely, because then one would expect more leaching with HZSM-5(358K) due to the higher treatment temperature. Another possible explanation is the re-alumination of the zeolite structure with extraframework $\mathrm{Al}$ species, an effect that is easier to happen at lower temperatures..$^{32}$ As can be seen in Figure 3, there are no peaks in the region between 30 to $35 \mathrm{ppm}$ due to pentacoordinate aluminum species and, therefore, these species were not included in the present discussion.

The $\mathrm{N}_{2}$ adsorption-desorption isotherms of the zeolites are shown in Figure 4a. In all samples, a H4 hysteresis loop has been observed at high relative pressures, typical of zeolite crystals with some degree of mesoporosity. ${ }^{52}$ After the HZSM-5 zeolite was treated with alkali solution, the hysteresis loop becomes more pronounced due to the creation of mesopores. ${ }^{48,53}$

From the adsorption BJH graph (Figure 4b), it is possible to confirm mesopore formation, with a modal maximum around $30.1 \mathrm{~nm}$ in HZSM-5(358K) and $18.3 \mathrm{~nm}$ in HZSM-5(338K). As shown in Table 2, the untreated zeolite contains a smaller amount of mesopores, probably related to defects in the zeolite structure resulting in small mesopores between ca. 2 and $4 \mathrm{~nm}$. After the $\mathrm{NaOH}$ 

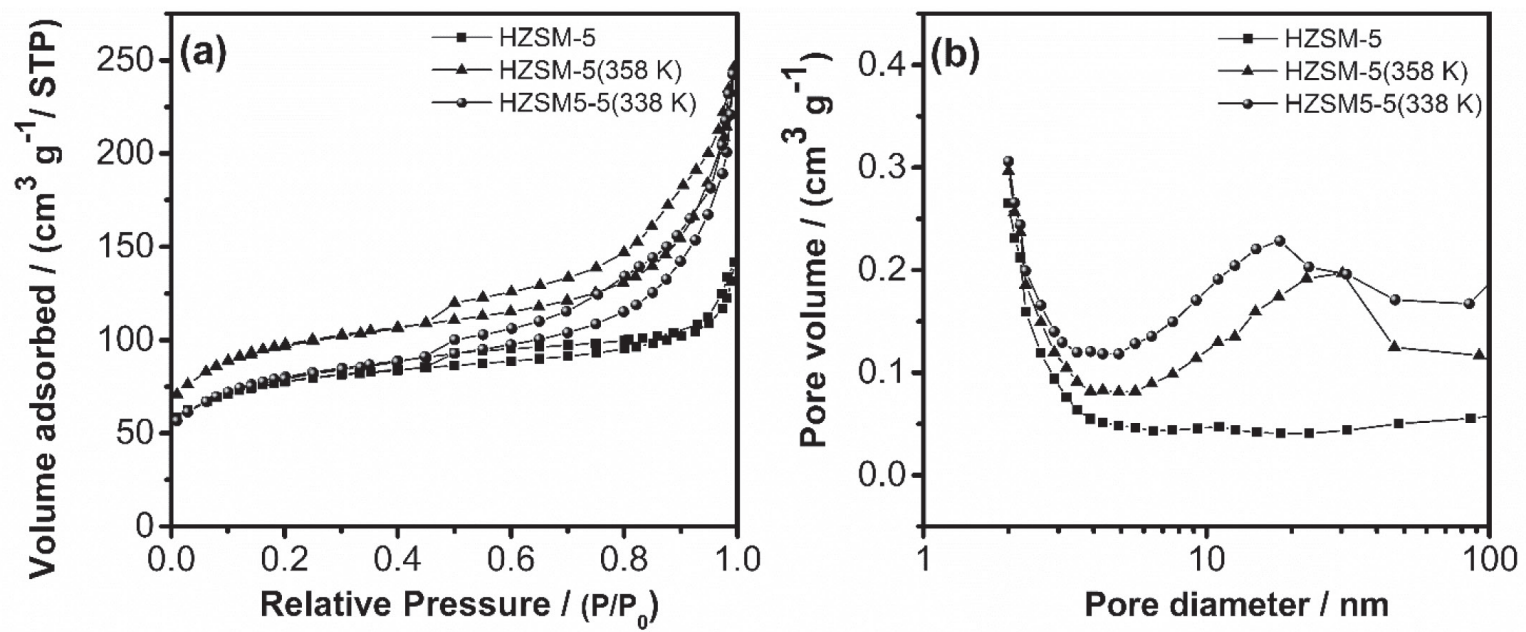

Figure 4. $\mathrm{N}_{2}$ adsorption isotherms and pore size distributions for the HZSM-5 and desilication zeolites.

treatment, the mesopore values $\left(\mathrm{V}_{\text {meso }}\right.$ and $\left.\mathrm{S}_{\text {meso }}\right)$ have increased in comparison to the untreated zeolite.

The XRD pattern of the ZSM-5 structure (Figure 5) is preserved after the desilication. The small changes in relative crystallinity (Table 2) are due to partial removal of $\mathrm{Si}$ from the framework, defects generation and amorphous material deposition.

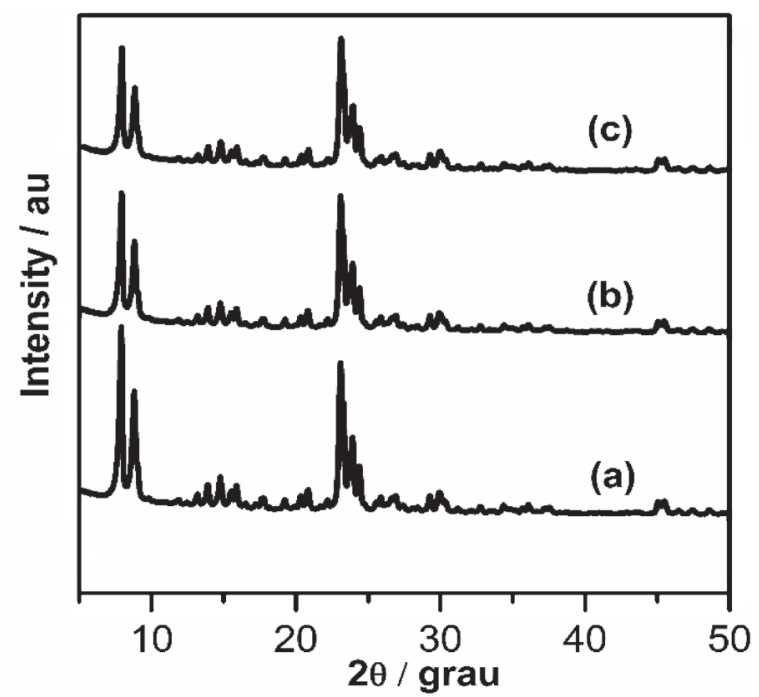

Figure 5. X-ray diffraction patterns for zeolites. Where (a) HZSM-5; (b) HZSM-5(358K) and (c) HZSM-5(338K).

Figure 6 shows the $\mathrm{OH}$ stretching region of the IR spectra for the micro and mesoporous zeolites. In the untreated sample, there are three separate and well-defined peaks at 3742,3611 , and $3460 \mathrm{~cm}^{-1}$.

The peak at $3742 \mathrm{~cm}^{-1}$ corresponds to the silanol groups $(\mathrm{SiOH})$ located at the outer surface or mesopore walls of the zeolite. At $3611 \mathrm{~cm}^{-1}$ bands due to bridged $\mathrm{Si}(\mathrm{OH}) \mathrm{Al}$ hydroxyls that are responsible for the Brønsted (BAS) acidity of the zeolites appear. Finally, another peak at

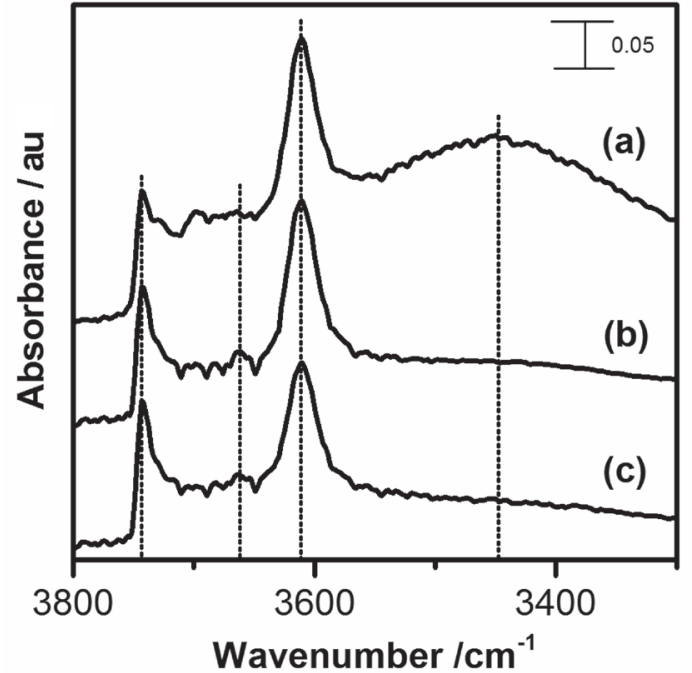

Figure 6. IR spectra at the $\mathrm{OH}$ stretching region of supports. (a) HZSM-5, (b) HZSM-5(358K) and (c) HZSM-5(338K).

$3460 \mathrm{~cm}^{-1}$ corresponds to $(-\mathrm{SiOH})_{4}$ groups, located within the zeolite structure, interacting through hydrogen bonds in the configurations known as "silanol nests" associated with imperfections of the zeolite structure..$^{54}$ The peaks located between $3650-3700 \mathrm{~cm}^{-1}$, which are less intense and less distinguishable, correspond to $\mathrm{OH}$ groups in extraframework aluminum species..$^{55}$

Due to the treatment with $\mathrm{NaOH}$, changes in the $\mathrm{OH}$ stretching region of the Fourier transform infrared spectroscopy (FTIR) are observed. The band at $3746 \mathrm{~cm}^{-1}$ $(\mathrm{SiOH})$ has its intensity increased, as mesoporous samples contain more silanol groups, and this increase may be associated with changes in the mesopore area or crystal size. ${ }^{54,56}$ The largest difference between the untreated sample and the mesoporous zeolites is the complete suppression of the broadband at $3460 \mathrm{~cm}^{-1}$ after the alkali treatment. It can be deduced that the silanol groups in 
nests are more susceptible to alkaline reaction, results also observed by Holm et al..$^{54}$ and Gil et al. ${ }^{51}$

The nature (Brønsted or Lewis) of the acidic sites of the zeolites was studied by adsorbed pyridine FTIR spectroscopy. The obtained spectra are shown in Figure 7.

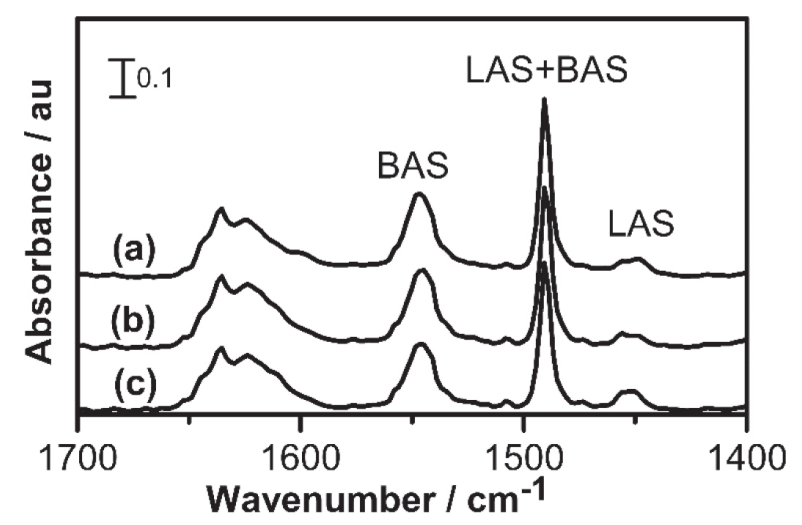

Figure 7. IR spectra at the ring deformation region of adsorbed pyridine for the zeolites. (a), HZSM-5; (b), HZSM-5(358K); (c), HZSM-5(338K).

The concentration of Lewis (LAS) and Brønsted (BAS) acid sites were determined, respectively, from the peak intensities at $1540 \mathrm{~cm}^{-1}$ (protonated pyridine on Brønsted sites), and the band at $1456 \mathrm{~cm}^{-1}$ (pyridine coordinated to Lewis sites) after desorption at $525 \mathrm{~K}$, using the equation reported by Emeis ${ }^{57}$ and molar extinction coefficients reported by Rodrigues et al. ${ }^{49}$ The results are displayed in Table 5 and show a decrease in the number of Brønsted acid sites (BAS) by $\mathrm{NaOH}$ treatment.

Table 5. Acidic properties of supports from pyridine adsorbed FTIR spectroscopy

\begin{tabular}{lccc}
\hline \multirow{2}{*}{ Catalyst } & \multicolumn{3}{c}{ Acidity $^{\mathrm{a}} /\left(\mu \mathrm{mol} \mathrm{Py} \mathrm{g}{ }^{-1}\right)$} \\
\cline { 2 - 4 } & BAS & LAS & LAS + BAS \\
\hline HZSM-5 & 307 & 15 & 322 \\
HZSM-5(358K) & 298 & 41 & 338 \\
HZSM-5(338K) & 289 & 40 & 328 \\
\hline
\end{tabular}

a Calculated using the extinction coefficients by Rodrigues et al. ${ }^{49}$ Py: pyridine; LAS: Lewis acid sites; BAS: Brønsted acid sites.

The decrease in the BAS concentration is larger at the lower temperature $(338 \mathrm{~K})$ treated sample. However, this result is not in line with the $\% \mathrm{O}_{\mathrm{h}} \mathrm{Al}$ (cf., Table 4). One possible explanation is that, since BAS have bridged hydroxyls between an $\mathrm{Al}$ and a $\mathrm{Si}$ atom, $\mathrm{Si}$ removal also leads to the destruction of the BAS without producing octahedrically coordinated aluminum. ${ }^{58}$

The concentration of Lewis acid sites increased significantly with the alkali treatment and is approximately the same in the two desilicated zeolites, irrespectively of the temperature used in the treatment. This bears no correlation with the amount of octahedrally coordinated aluminum and, therefore, Lewis acidity does not seem to arise only from this kind of species.

\section{Conclusions}

Desilication with alkali solution provides a simple and effective way of producing mesoporous ZSM-5 catalysts. The factorial design results showed that all principal factors (temperature, reaction time and alkali concentration) and the second-order interaction between temperature and reaction time have statistical significance to the micropore volumes.

While factors temperature and concentration lead to a micropore volume reduction due to the presence of amorphous $\mathrm{Si}$-rich debris and the increase in the rate of desilication, reaction time and its interaction with temperature lead to an increase in the micropore volume by an annealing effect.

Only factors related to reaction time and alkali concentration have a relevant effect in the mesopore volumes. On the other hand, increases in reaction time and alkali concentration influenced positively the mesopore volumes, due to increased silicon leaching from the zeolite structure and the necessity of more time to connect the defects created in a mesopore network. The first order interaction between these variables has a negative impact on this response, indicating that simultaneous increase in both factors does not lead to an extra increase in the response.

The mesopore area response showed the same behavior regarding reaction time and concentration as the mesopore volume, however, the second order interaction between these variables was statistically insignificant. Only the alkali concentration has statistical significance to the crystallinity response indicating the importance of silicon etching to the zeolite crystal structure preservation.

After the desilication treatment, a lower $\mathrm{Si} / \mathrm{Al}$ ratio was observed as compared to the untreated zeolite, demonstrating the preferential dissolution of Si. An increase in the pore diameter was observed in all cases, especially when the ZSM-5 zeolite was treated at a high temperature $(358 \mathrm{~K})$.

A decrease in the framework $\mathrm{Si} / \mathrm{Al}$ ratio, as shown by NMR techniques, and the complete suppression of the broadband at $3460 \mathrm{~cm}^{-1}$ in the zeolites IR spectra after the desilication treatment showed that silanol groups in nests were more susceptible to basic hydrolysis. In all cases, an increase in Lewis acid sites concentration and a decrease in the Brønsted acid sites concentration was observed, as seen by both adsorbed pyridine and $\mathrm{OH}$ stretching FTIR, which resulted from alkali leaching of Si sites neighboring $\mathrm{Al}$ atoms. 


\section{Supplementary Information}

Supplementary information is available free of charge at http://jbcs.sbq.org.br as PDF file.

\section{Acknowledgments}

The authors acknowledge the XRD and NMR multiuser laboratories at IQ-UFRJ for sample analysis. ACFJ thanks CNPq for a productivity research scholarship. HJM thanks CAPES for a DSc scholarship. The authors also thank CNPq for the financial support (grant 426600/2018-5). This study was financed in part by the Coordenação de Aperfeiçoamento de Pessoal de Nível Superior Brazil (CAPES) finance code 001.

\section{Author Contributions}

The manuscript was written through contributions of all authors. All authors have given approval to the final version of the manuscript. All authors contributed equally.

\section{References}

1. Corma, A.; Martinez, A. In Zeolites for Cleaner Technologies, vol. 3, $3^{\text {rd }}$ ed.; Guisnet, M.; Gilson, J.-P., ed.; Press, Imperial College: New York, 2002, ch. 2.

2. Maesen, T.; Čejka, J.; van Bekkum, H.; Corma, A.; Schüth, F. In Introduction to Zeolite Science and Practice, $3^{\text {rd }}$ ed.; Schüth, F., ed.; Elsevier: Amsterdam, 2007.

3. Sherman, J. D.; Proc. Natl. Acad. Sci. U.S.A. 1999, 7, 3471.

4. Tao, Y.; Kanoh, H.; Abrams, L.; Kaneko, K.; Chem. Rev. 2006, $106,896$.

5. Nogueira, H. P.; Toma, S. H.; Silveira Jr., A. T.; Araki, K.; J. Braz. Chem. Soc. 2020, 31, 2342.

6. Ferrarini, S. F.; Cardoso, A. M.; Alban, L.; Pires, M. J. R.; J. Braz. Chem. Soc. 2018, 29, 1464.

7. Arroyo-Martínez, P. C.; Sánchez-Flores, N. A.; VillafuerteCastrejón, M. E.; Vivar-Ocampo, R.; J. Braz. Chem. Soc. 2018, 29,58 .

8. Maxwell, I. E.; Stork, W. H. J. In Introduction to Zeolite Science and Practice, $58^{\text {th }}$ ed.; Flanigen, E. M.; van Bekkum, H.; Jansen, J. C., eds.; Elsevier: Amsterdam, 1991, ch. 15.

9. Tanabe, K.; Hölderich, W. F.; Appl. Catal., A 1999, 181, 399.

10. Li, Y.; Liu, S.; Zhang, Z.; Xie, S.; Zhu, X.; Xu, L.; Appl. Catal., A 2008, 338, 100.

11. Srivastava, R.; Choi, M.; Ryoo, R.; Chem. Commun. 2006, 41, 4489.

12. Clemente, M. C. H.; Valadares, D. S.; Lacava, A. B.; Barbosa, L. S.; Martins, G. A. V.; Dias, J. A.; Dias, S. C. L.; J. Braz. Chem. Soc. 2019, 30, 2182.
13. Silva, B. J. B.; Sousa, L. V.; Sarmento, L. R. A.; Carvalho, R. P.; Quintela, P. H. L.; Pacheco, J. G. A.; Fréty, R.; Silva, A. O. S.; Microporous Mesoporous Mater. 2019, 290, 109647.

14. Corma, A.; J. Catal. 2003, 216, 298.

15. Jacobs, P.; Martens, J. A.; Stud. Surf. Sci. Catal. 1991, 58, 445.

16. Weitkamp, J.; Solid State Ionics 2000, 131, 175.

17. Degnan, T. F.; J. Catal. 2003, 216, 32.

18. Guisnet, M.; Ribeiro, F. R. In Zeólitos: um Nanomundo ao Serviço da Catálise, $1^{\text {st }}$ ed.; Gulbenkian, F. C., ed.; Fundação Calouste Gulbenkian: Lisboa, 2004.

19. Wang, X.; Jacobson, A. J.; Mater. Res. Soc. Symp. Proc. 2001, 658, GG8.1.

20. Pérez-Ramírez, J.; Christensen, C. H.; Egeblad, K.; Christensen, C. H.; Groen, J. C.; Chem. Soc. Rev. 2008, 37, 2530.

21. Hartmann, M.; Angew. Chem. 2004, 43, 5880.

22. Kim, J.; Choi, M.; Ryoo, R.; J. Catal. 2010, $269,219$.

23. Kowalska-Kuś, J.; Held, A.; Nowińska, K.; ChemCatChem 2020, 12,510 .

24. Ryoo, R.; Kim, J.; Jo, C.; Han, S. W.; Kim, J. C.; Park, H.; Han, J.; Shin, H. S.; Shin, J. W.; Nature 2020, 585, 221.

25. Holm, M. S.; Taarning, E.; Egeblad, K.; Christensen, C. H.; Catal. Today 2011, 168, 3.

26. Serrano, D. P.; Escola, J. M.; Pizarro, P.; Chem. Soc. Rev. 2013, 42,4004 .

27. Na, K.; Choi, M.; Ryoo, R.; Microporous Mesoporous Mater. 2013, 166, 3 .

28. Ryoo, R.; Joo, S. H.; Jun, S.; J. Phys. Chem. B 1999, 103, 7743.

29. Jacobsen, C. J. H.; Madsen, C.; Houzvicka, J.; Schmidt, I.; Carlsson, A.; J. Am. Chem. Soc. 2000, 122, 7116.

30. Gamliel, D. P.; Cho, H. J.; Fan, W.; Valla, J. A.; Appl. Catal., A 2016, 522, 109.

31. Jia, X.; Khan, W.; Wu, Z.; Choi, J.; Yip, A. C. K.; Adv. Powder Technol. 2019, 30, 467.

32. Verboekend, D.; Pérez-Ramírez, J.; Catal. Sci. Technol. 2011, 1,879 .

33. van Donk, S.; Janssen, A. H.; Bitter, J. H.; de Jong, K. P.; Catal. Rev.: Sci. Eng. 2003, 45, 297.

34. Groen, J. C.; Moulijn, J. A.; Pérez-Ramírez, J.; J. Mater. Chem. 2006, 16, 2121.

35. Corma, A.; Fornes, V.; Pergher, S. B.; Maensen, L. M.; Buglass, J. G.; Nature 1998, 396, 353.

36. Abelló, S.; Pérez-Ramirez, J.; Phys. Chem. Chem. Phys. 2009, $11,2794$.

37. Čimeka, A.; Subotić, B.; Šmit, I.; Tonejc, A.; Aielloc, R.; Crea, F.; Nastro, A.; Microporous Mater. 1997, 8, 159.

38. Groen, J. C.; Peffer, L. A. A.; Moulijn, J. A.; Pérez-Ramírez, J.; Colloids Surf., A 2004, 241, 53.

39. Wei, X.; Smirniotis, P. G.; Microporous Mesoporous Mater. 2006, 97, 97.

40. Mokrzycki, Ł.; Sulikowski, B.; Olejniczak, Z.; Catal. Lett. 2009, 127, 296. 
41. Sommer, L.; Mores, D.; Svelle, S.; Stöcker, M.; Weckhuysen, B. M.; Olsbye, U.; Microporous Mesoporous Mater. 2010, 132, 384.

42. Verboekend, D.; Chabaneix, A.; Thomas, K.; Gilson, J.; PérezRamirez, J.; CrystEngComm 2011, 13, 3408.

43. Lopez-Orozco, S.; Inayat, A.; Schwab, A.; Selvam, T.; Schwieger, W.; Adv. Mater. 2011, 23, 2602.

44. Gackowski, M.; Podobiński, J.; Broclawik, E.; Datka, J.; Molecules 2020, 25, 31.

45. Groen, J.; Zhu, W.; Brouwer, S.; Huynink, S.; Kapteijn, F.; Moulijn, J.; Pérez, J.; J. Am. Chem. Soc. 2007, 129, 355.

46. Tempelman, C. H. L.; Rodrigues, V. O.; van Eck, E.; Magusin, P. C. M. M.; Hensen, E. J. M.; Microporous Mesoporous Mater. 2015, 203, 259.

47. Treacy, M. M.; Higgins, J. B. Collection of Simulated XRD Powder Patterns for Zeolites, $4^{\text {th }}$ ed.; Elsevier: Amsterdam, 2001.

48. Rac, V.; Rakíc, V.; Miladinovíc, Z.; Stošić, D.; Auroux, A. A.; Thermochim. Acta 2013, 567, 73.

49. Rodrigues, V. O.; Eon, J.-G.; Faro Jr., A. C.; J. Phys. Chem. C 2010, 114, 4557.
50. Fricke, R.; Kosslick, H.; Lischke, G.; Richter, M.; Chem. Rev. 2000, 100, 2303

51. Gil, B.; Mokrzycki, Ł.; Sulikowski, B.; Olejniczak, Z.; Walas, S.; Catal. Today 2010, 152, 24.

52. Thommes, M.; Kaneko, K.; Neimark, A. V.; Olivier, J. P.; Rodriguez-Reinoso, F.; Rouquerol, J.; Sing, K. S. W.; Pure Appl. Chem. 2015, 87, 1051.

53. Groen, J. C.; Bach, T.; Ziese, U.; Paulaime-Van Donk, A. M.; de Jong, K. P.; Moulijn, J. A.; Pérez-Ramírez, J.; J. Am. Chem. Soc. 2005, 127, 10792.

54. Holm, M.; Svelle, S.; Joensen, F.; Beato, P.; Chistensen, C.; Bordiga, S.; Bjørgen, M.; Appl. Catal., A 2009, 356, 23.

55. Trombetta, M.; Armaroli, T.; Gutiérrez, A.; Ramirez, J.; Busca, G.; Appl. Catal., A 2000, 192, 125.

56. Su, B.-L.; Norberg, V.; Zeolites 1997, 19, 65.

57. Emeis, C. A.; J. Catal. 1993, 141, 347.

58. Verboekend, D.; Mitchell, S.; Milina, M.; Groen, J. C.; PérezRaimirez, J.; J. Phys. Chem. C 2011, 14193.

Submitted: October 6, 2020 Published online: February 10, 2021 